\title{
Effects of processing parameters on mechanical, material flow and wear behaviour of friction stir welded 6101-T6 and 7075-T651 aluminium alloys
}

\author{
Olatunji P. Abolusoro* and Esther T. Akinlabi \\ Department of Mechanical Engineering Science, University of Johannesburg, Johannesburg, South Africa
}

Received: 12 October 2019 / Accepted: 26 November 2019

\begin{abstract}
Dissimilar friction stir welding (FSW) between 6101-T6 and 7075-T651 aluminium alloys was conducted. Three different parameters each were investigated for rotational speed and travel speed, and the effects of these parameters on the tensile behaviour, hardness and wear were evaluated. The results indicate that the ultimate tensile strength increases with an increase in the feed rate. However, the increase in rotational speed decreases the ultimate tensile values. The fractured analysis of the tensile samples shows similarities in the fractured pattern as all the samples failed at heat affected zone close to the 6101-T6 alloy. The hardness varies across the heat affected zones and nugget zone both at constant rotational speed and welding speeds. The highest resistance to wear occurred at $65 \mathrm{~mm} \mathrm{~min}^{-1}$ and $1850 \mathrm{rpm}$ welding speed and rotational speed respectively while better material mixing was achieved at the nugget zone of the welds at $1250 \mathrm{rpm}$ and $110 \mathrm{~mm} / \mathrm{min}$.
\end{abstract}

Keywords: Aluminium alloys / friction stir welding / mechanical properties / process parameters / wears

\section{Introduction}

One of the best technologies that have been identified to join low-temperature alloys especially aluminium is the friction stir welding (FSW). This welding technology emanated in 1991 and have been successfully employed to join aluminium alloy in many applications such as in marine, military, automotive and aerospace industries. The FSW utilized a rotating tool which has a pin and a shoulder. When this tool rotates on a workpiece, friction occurred which generates the heat needed to plasticized the material at the joint interface, permitting the stirring of the material by the rotating tool pin. The pressure from the tool shoulder and the mixing of materials by the tool bonded the workpiece interface together [1-8]. The heat generated during FSW alters the mechanical properties of the weld through microstructural modifications. This modification is often influenced by the processing parameter employed for the welding [8-10]. It has, therefore, become imperative to understand the influence of these parameters on the quality of welds. Particular attention has been given to the study of the relationship between mechanical properties and process parameters by researchers. Asadi and Givi [11] established how process parameters such as feed rate and tool rotational speed as well as tool

\footnotetext{
* e-mail: abolusoroolatunji@yahoo.com
}

profile affect the mechanical behaviour of welds. Tool rotational speed effects on tensile behaviour have been reported by some authors. For example, Lombard et al. [12] optimized the process parameters of friction stir welded 5083-H321 aluminium alloy in order to minimise defects and maximise fatigue life. Eleven parameters of combinations of rotational and traverse speeds were used. The tensile results obtained show that $200 \mathrm{rpm}$ rotational speed and $85 \mathrm{~mm} / \mathrm{min}$ travel speed gave the highest tensile value of $313 \mathrm{Mpa}$. The study portrayed that the major processing parameter affecting tensile strength is the rotational speed. Min-Su Han et al. [13] however reported that excess rotational speed could generate defects and improper joining. Prabha et al. [14] also investigated the influence of tool rotational speed on the tensile strength of 5083 aluminium alloy and concluded that rotational speed of $1120 \mathrm{rpm}$ gave the best tensile results out of two other speeds of 1400 and $1800 \mathrm{rpm}$ used. Aydin et al. [15] also identified tool rotational speed as a significant FSW variable which affects the rate of strain and the process of recrystallization. Ghosh et al. [16] reported an improvement in joint strength of FSW of dissimilar A356 and 6061 aluminium alloys welded with low travel and rotational speeds. In addition, Hariharan and Nimal [17] joined AA6061 and AA7075 aluminium alloys via FSW using a computerized numerical control machine. They reported an optimized tool rotational speeds of $1250 \mathrm{rpm}$ and travel speed of $120 \mathrm{~mm} / \mathrm{min}$ to give a defect free welds. Also, 
Table 1. Chemical composition of the welded aluminium alloys.

\begin{tabular}{llllllllll}
\hline Alloy & $\mathrm{Si}$ & $\mathrm{Cu}$ & $\mathrm{Fe}$ & $\mathrm{Mn}$ & $\mathrm{Mg}$ & $\mathrm{Ti}$ & $\mathrm{Cr}$ & $\mathrm{Zn}$ & $\mathrm{Al}$ \\
\hline 6101-T6 & 0.53 & 0.01 & 0.14 & 0.002 & 0.600 & 0.008 & 0.001 & 0.003 & Others \\
7075-T651 & 0.40 & 1.70 & 0.50 & 0.300 & 2.40 & 0.20 & 0.22 & 5.50 & Others \\
\hline
\end{tabular}

Table 2. Mechanical properties of the welded alloys.

\begin{tabular}{llll}
\hline Alloy & $\begin{array}{l}\text { Tensile } \\
\text { strength } \\
(\mathrm{MPa})\end{array}$ & $\begin{array}{l}\text { Ultimate tensile } \\
\text { strength }(\mathrm{MPa})\end{array}$ & $\begin{array}{l}\text { Elongation } \\
(\%)\end{array}$ \\
\hline $6101-\mathrm{T} 6$ & 172 & 200 & 15 \\
$7075-\mathrm{T} 651$ & 462 & 575 & 11 \\
\hline
\end{tabular}

Danielos and Pantelis [18] reported a good material mixing and mechanical properties at $950 \mathrm{rpm}$ and $47.5 \mathrm{~mm} / \mathrm{min}$ rotational and travel speed respectively in the FSW of 6082 and 7075-T651 aluminium alloys. Another work by Cole et al. [19] on FSW of 7075 and 6061 revealed an improvement in the joint strength at lower heat input. A similar work carried out by Guo et al. [20] shows that an increase in the welding speed which led to heat input reduction produced a higher UTS. Koilraj et al. [21] predicted mechanical strength of FSW of some aluminium alloys using Taguchi method. Rajkumar et al. [22] equally revealed that there exists a range of tool rotational speed where weld quality can be guaranteed. This demonstrates the possibilities of optimizing these process parameters of FSW in order to obtain high weld quality. Elangova et al. [23] showed the relationship between high welding speed and heat input. Heat input affects the metallurgical evolution that occurred during welding. And therefore, affect the strength across the zones of the weld. On this basis, an appropriate combination of the feed rate and the rotational speed of the tool can be said to be a significant factor for FSW control that determines the mechanical properties of the welded joint. Another significant factor affecting good mechanical strength, good material mixing and bonding in dissimilar aluminium friction stir welding is the relative positions of the alloys during the welding $[18,24]$. For instance, Guo et al. [20] noted a better material mixing condition at the nugget zone of the weld when the softer alloy (6061) is placed on the advancing side while the harder one (7075) is kept on the retreating side during the FSW of both alloys. Some reseachers have also reported that the thermal profile generated along the weld and the material movement and flow pattern are influenced by which of the dissimilar materials are kept on the advancing or retreating side of the welds [25]. Wear behaviour in some friction stir welded alloys have also been investigated by some researchers. Won Bae Lee et al. [26] investigated wear characteristics of FSW AZ91 magnesium alloy reinforced with silicon particles. Their result showed that better resistance to wear occurred at the welded zone compares to
Table 3. Rotational speeds and travel speeds.

\begin{tabular}{ll}
\hline $\begin{array}{l}\text { Rotational } \\
\text { speed }(\mathrm{rpm})\end{array}$ & $\begin{array}{l}\text { Travel speed } \\
\left(\mathrm{mm} \mathrm{min}^{-1}\right)\end{array}$ \\
\hline 1250 & 20 \\
1250 & 65 \\
1250 & 110 \\
1550 & 110 \\
1850 & 110 \\
\hline
\end{tabular}

the parent metals. Palanivel et al. [27] established an empirical relationship between process parameters and wear resistance in the FSW of AA5083H111-AA6351-T6 alloys. Their result indicates that resistance to wear increases as tool rotational and welding speed increases to a certain extent after which the reverse occurred. This finding was in agreement with Dinaharan et al. [28] study on wear behaviour of FSW of AA6061/0-10wt\% $\mathrm{ZrB}_{2}$ composites. Seyed et al. [29] studied wear behaviour of similar and dissimilar FSW of AA6082 and AA6061 alloy. Their report indicates that similar welds of AA6061 gave superior wear resistance at the nugget zone to those of similar weld of AA6082 and dissimilar welds of both alloys. However, the dissimilar welds performed better at nonwelded zone. This result was in agreement with similar investigations on the wear of FSW of AA6061 and AA6082 carried out by Khaja et al. [30]. The influence of Process parameters often differs in dissimilar friction stir welding of aluminium alloys and have not been fully studied. This work is an effort to give more understanding of the process as it relates to mechanical properties, material flow and wear behaviour in dissimilar welding of aluminium alloys.

\section{Experimental procedure}

\subsection{Sample's chemical composition and properties}

The elemental composition and mechanical properties of the welded alloys are shown in Tables 1 and 2, respectively.

\subsection{Process parameters}

The rotational and travel speeds used for the experiments are shown in Table 3 . The parameters were chosen based on the optimized parameters on similar work reported in the literature [31]. The rotational and the travel speeds range were carefully selected to cover below and above the reported optimized values. 


\subsection{Experimental procedure}

\subsubsection{Welding set up}

The aluminium plates $6101-\mathrm{T} 6$ and 7075 -T651 with a thickness of $6 \mathrm{~mm}$ to be welded were cut into pieces of $60 \mathrm{~mm} \times 100 \mathrm{~mm}$ each. The edges to be joined were milled to allow proper lapping when placed in the welding position. The surface especially the areas to be welded were cleaned with very smooth emery paper to remove oxide layers that might have been formed on the surfaces of the alloys. Acetone was further used to clean the surface to (a)

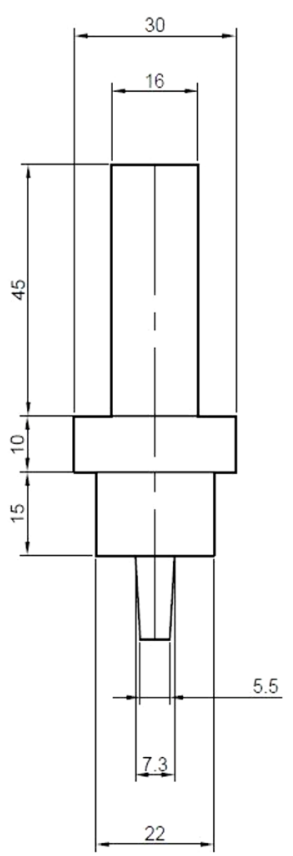

(b)

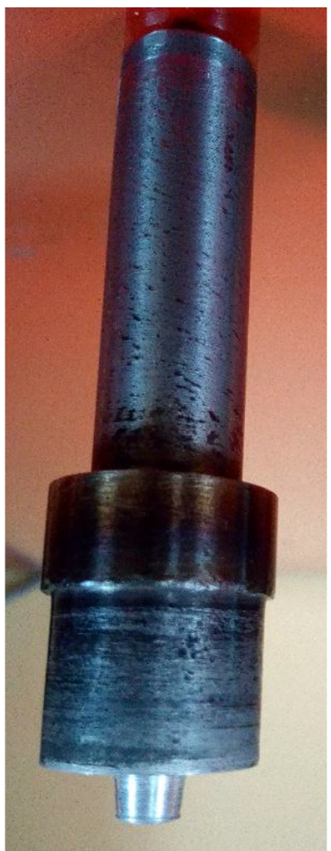

Fig. 1. Tapered threaded tool (a) schematic diagram (b) picture. remove dirt and oil or grease. A cylindrical tapered tool having shoulder diameter of $22 \mathrm{~mm}$, probe length $5.65 \mathrm{~mm}$, with root and mouth diameter of $7.3 \mathrm{~mm}$ and $5.5 \mathrm{~mm}$, respectively as shown in Figure 1a and b was used for the welding. The welding was carried out with a two-tonne numerical welding machine manufactured by ETA Technology Ltd, Bangalore, India (Fig. 2a). The plates were arranged in butt configuration with the 6101-T6 placed on the advancing side (AS) while the 7075-T651 alloy was placed on the retreating side (RS). The plates were clamped in this arrangement for the welding as shown in Figure 2b. The welding was performed in the rolling directions of the plates. The welding parameters shown in Table 3 were utilized for the welding. Other parameters used are plunge depth of $0.15 \mathrm{~mm}$ and tool tilt angle of $2^{\circ}$.

\subsubsection{Mechanical testing of the welds}

Three tensile samples from each weld as shown in Figure 3 were cut perpendicularly to the weld following ASTM E8 standard specifications for mechanical strength evaluation. The tensile testing was carried out as a function of tool rotational and travel speeds using Instron testing machine. SEM fractography analysis was done on the tensile tested samples.

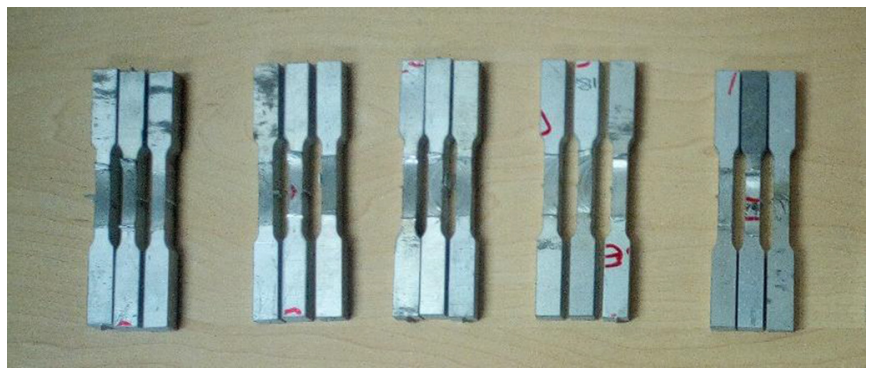

Fig. 3. Tensile samples evaluated.
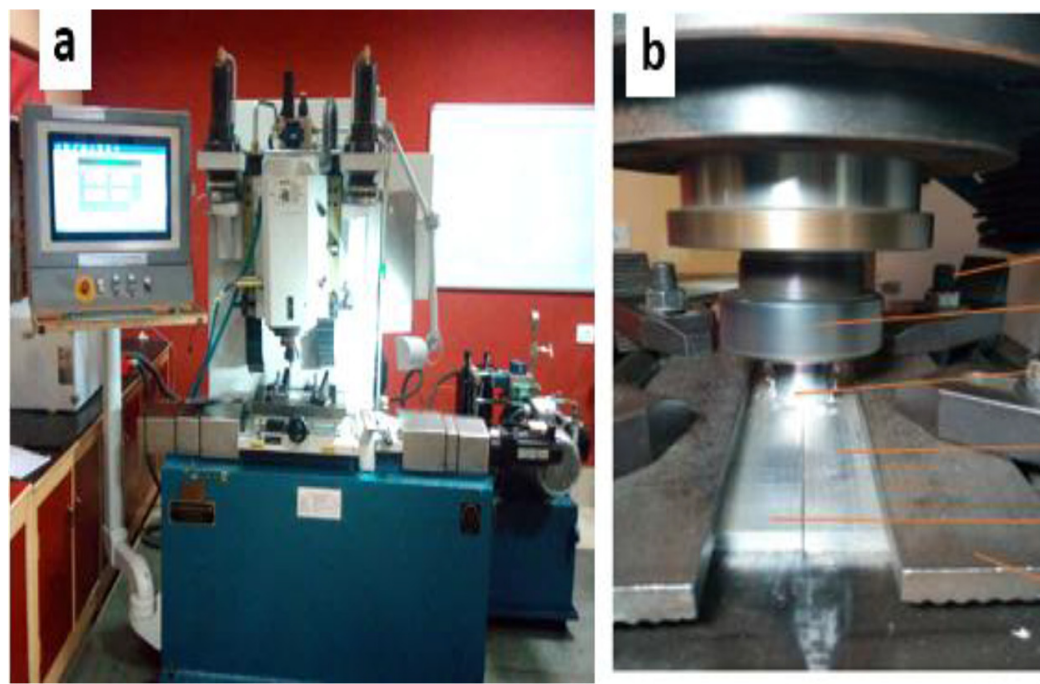

Clamping bolt Spindle Tool

Workpiece Advancing side (6101-T6) Workpiece Retrieving side (7075-T651)

Fig. 2. (a) Welding equipment. (b) Welding arrangement. 


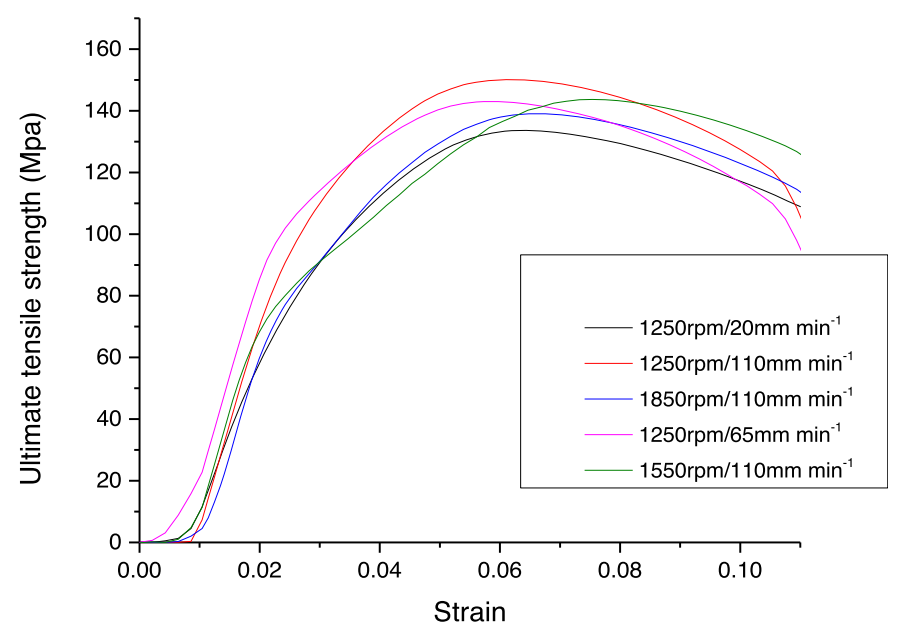

Fig. 4. Graph of stress vs strain at different process parameters.

\subsubsection{Hardness testing}

The hardness test was profiled across the welding direction. Vickers hardness testing equipment was used. $300 \mathrm{kgf}$ load was applied with a dwelling time of $15 \mathrm{~s}$ and 26 indentations were made on each sample at $1 \mathrm{~mm}$ interval.

\subsubsection{Wear testing}

The wear specimen measured $6 \mathrm{~mm} \times 6 \mathrm{~mm} \times 10 \mathrm{~mm}$ were cut from the nugget zone of the weld. A ball on disc machine of model E52100 with alloy steel ball of $6.35 \mathrm{~mm}$ diameter equipped with MFTI7 software was employed for the wear test under dry sliding conditions and at an ambient temperature of $25^{\circ} \mathrm{C}$ in accordance with ASTM G99 standard. A load of $20 \mathrm{~N}$ at a sliding distance of $3 \mathrm{~mm}$ for $300 \mathrm{~s}$ and velocity of $3 \mathrm{~mm} / \mathrm{s}$ were used. The worn surface analysis was carried out using a scanning electron microscope (SEM).

\section{Results and analysis}

\subsection{Tensile analysis}

The average stress-strain relationships obtained for all the process parameters are shown in Figure 4. While the effect of rotational speed and travel speed are respectively shown in Figures 5 and 6 . The detailed analysis of the results are fully discussed in this section.

\subsubsection{Effect of rotational speed on tensile behaviour}

The average values of the three tensile samples evaluated for each of the process parameters were plotted for the three different rotational speeds used in the study as shown in Figure 5. The rotational speed of $1250 \mathrm{rpm}$ at a travel speed of $110 \mathrm{~mm} \mathrm{~min}^{-1}$ gave the highest ultimate tensile strength of $150 \mathrm{MPa}$. The result shows that the ultimate tensile strength reduces with an increase in rotational speed. This can be attributed to more heat input into the weld from the frictional heat generated by the tool as the rotational speed increases. This trend was also observed by

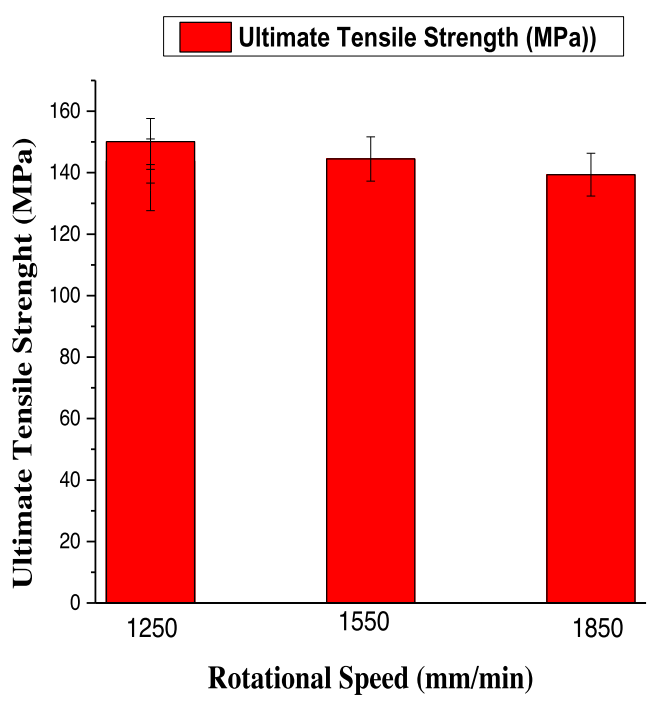

Fig. 5. Effects of rotational speed on ultimate tensile Strength with error bars at $95 \%$ confidence level.

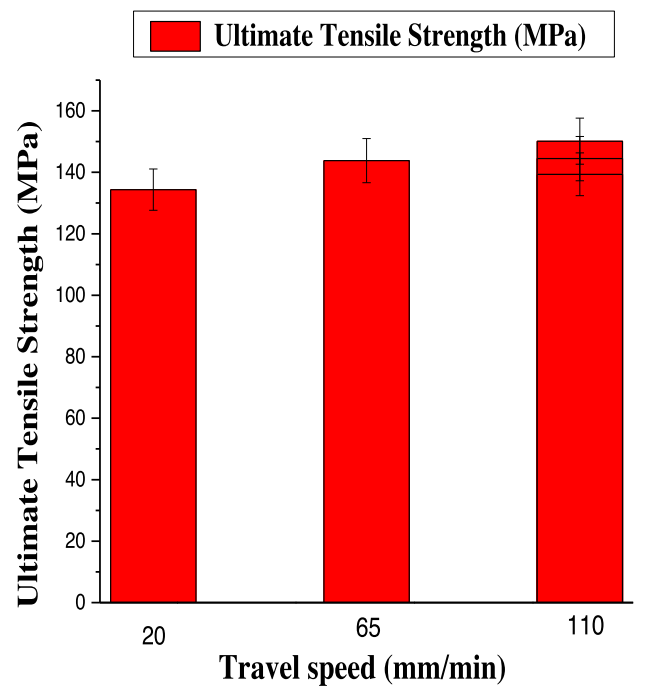

Fig. 6. Effects of travel speed on ultimate tensile strength with error bars at $95 \%$ confidence level.

Mohammed et al. [32] and Izabela et al. [33] with similar reasons given. The thermal cycle set up at the weld region own to heat input from the tool rotational speed becomes higher as the rotational speed increases. This causes deterioration of precipitates by coarsening or dissolutions at the welding zone and consequently lowers grain bonding thereby reducing the resultant mechanical properties of the weld $[8,18,19]$.

\subsubsection{Effect of travel speed on tensile behaviour}

At constant rotational speeds of $1250 \mathrm{rpm}$ and varying travel speed, the ultimate tensile values increases as the travel speed increases. This is illustrated in Figure 6. The 

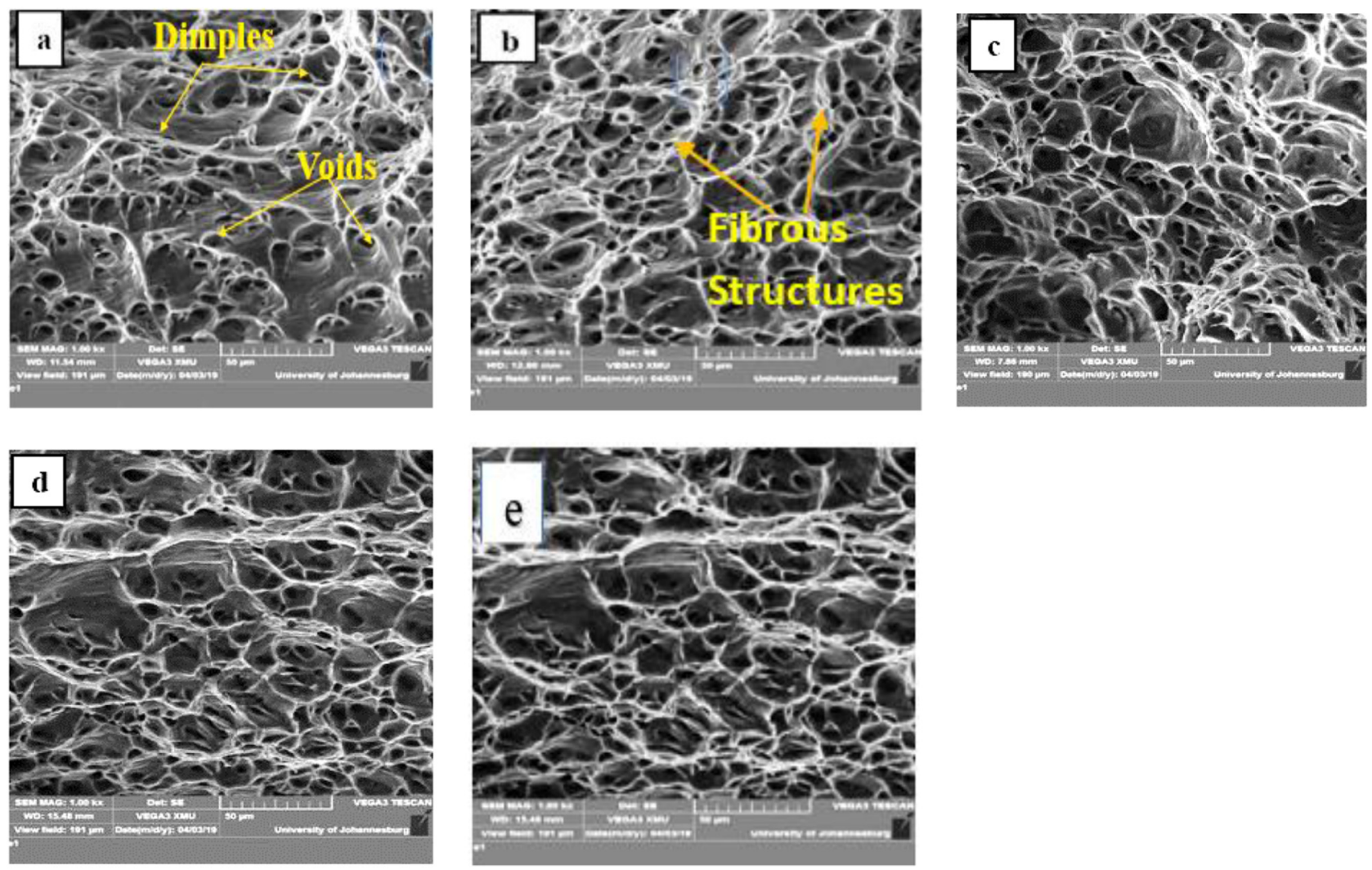

Fig. 7. Fractographs of the tensile tests fractured surfaces. (a) $1250 \mathrm{rpm}$ at $20 \mathrm{~mm} \mathrm{~min}^{-1}$. (b) $1250 \mathrm{rpm}$ at $65 \mathrm{~mm} \mathrm{~min}^{-1}$ (c) $1250 \mathrm{rpm}$ at $110 \mathrm{~mm} \mathrm{~min}^{-1}$. (d) $1550 \mathrm{rpm}$ at $110 \mathrm{~mm} \mathrm{~min}^{-1}$ (e) $1850 \mathrm{rpm}$ at $110 \mathrm{~mm} \mathrm{~min}^{-1}$.

travel speed of $110 \mathrm{~mm} \mathrm{~min}^{-1}$ being the highest used gave the highest ultimate tensile value of $150 \mathrm{MPa}$. This is as a result of less heat input into the weld due to less dwelling time of the tool rotation on the alloys as the travel speed increases. Higher travel speeds have been correlated to low heat input into the weld which led to faster cooling rates of the welded joints thereby promoting greater grain boundaries of precipitates which favours better mechanical properties $[18,34]$.

\subsubsection{Fracture analysis of the tested samples}

All the samples tested for tensile evaluations failed at the heat affected zone (HAZ) close to the 6101-T6 alloy placed on the advancing side during the welding. This can be attributed to the lower ultimate tensile strength possess by the 6101-T6 parent alloy compare to the other 7075-T651 alloy dissimilarly welded to it. The none failure of the material at the nugget zone suggest that proper material mixing and bonding occurred considerably within the range of rotational and travel speeds deployed for this study. Similar reasons were given by Daniolos and Pantelis [18]. The fractographs taken and shown in Figure 7a-e exhibits similarities in structures due to the fracture of the welds at the heat affected zone of the advancing side alloy for the range of rotational and travel speeds considered. The fractured samples also indicate that there was appreciable plastic deformation and necking before failure took place. Fibrous features with appreciable lip region at the outer boundary of the final fracture were noticeable. These fibrous features indicate that the crack propagation occurred slowly. The cracking pattern also exhibited what is termed equiaxed dimples with prominent cup and cone features, typical behaviour of ductile materials.

\subsection{Hardness analysis}

\subsubsection{Hardness at different welding speeds}

The hardness tests carried out on both parent alloys gave 60.01 and $178.8 \mathrm{Hv}$ for $6101-\mathrm{T} 6$ and 7075-T651, respectively. The hardness profile is shown in Figure 8 and the average hardness values obtained at different welding zones across the three welding speeds are shown in Figure 10. The hardness values obtained at the heat affected zone (HAZ) of the RS were lower than that of the parent alloy 7075-T651 at the RS. The subjection of the alloy to thermal cycle at that region during the welding could result in the dissolution of precipitates of the alloy leading to reduction of the hardness. The maximum average hardness value of $126.96 \mathrm{Hv}$ as illustrated in Figure 10 was obtained at the HAZ of the retreating side and occurred at the travel speed of $110 \mathrm{~mm} \mathrm{~min}^{-1}$ which is the highest welding speed employed. The less dwelling time of the tool as it traverses on the workpiece joint interface at the $110 \mathrm{~mm} \mathrm{~min}^{-1}$ welding speed promote better grain refinement at the region and may account for highest 


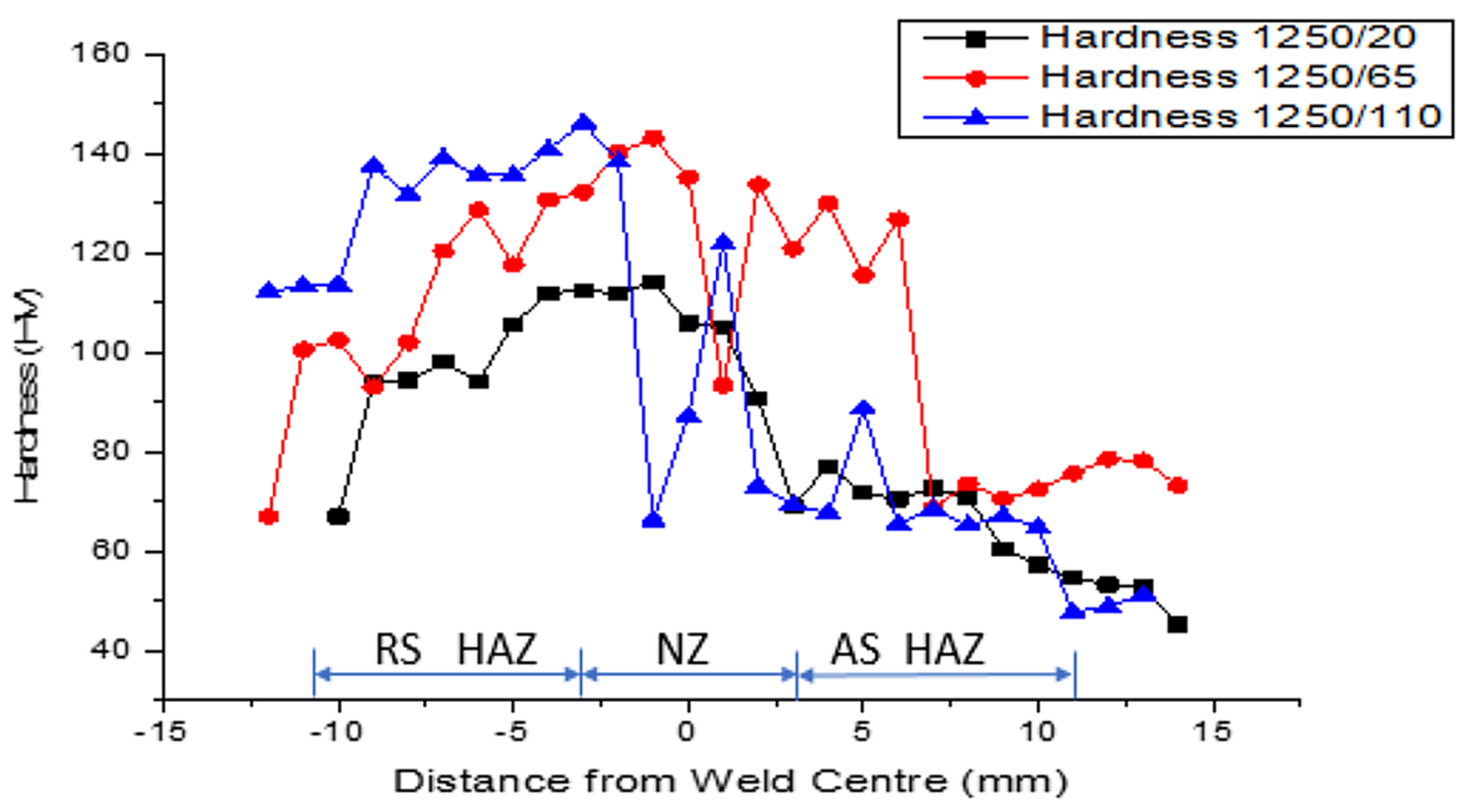

Fig. 8. Hardness profile at varying welding speed.

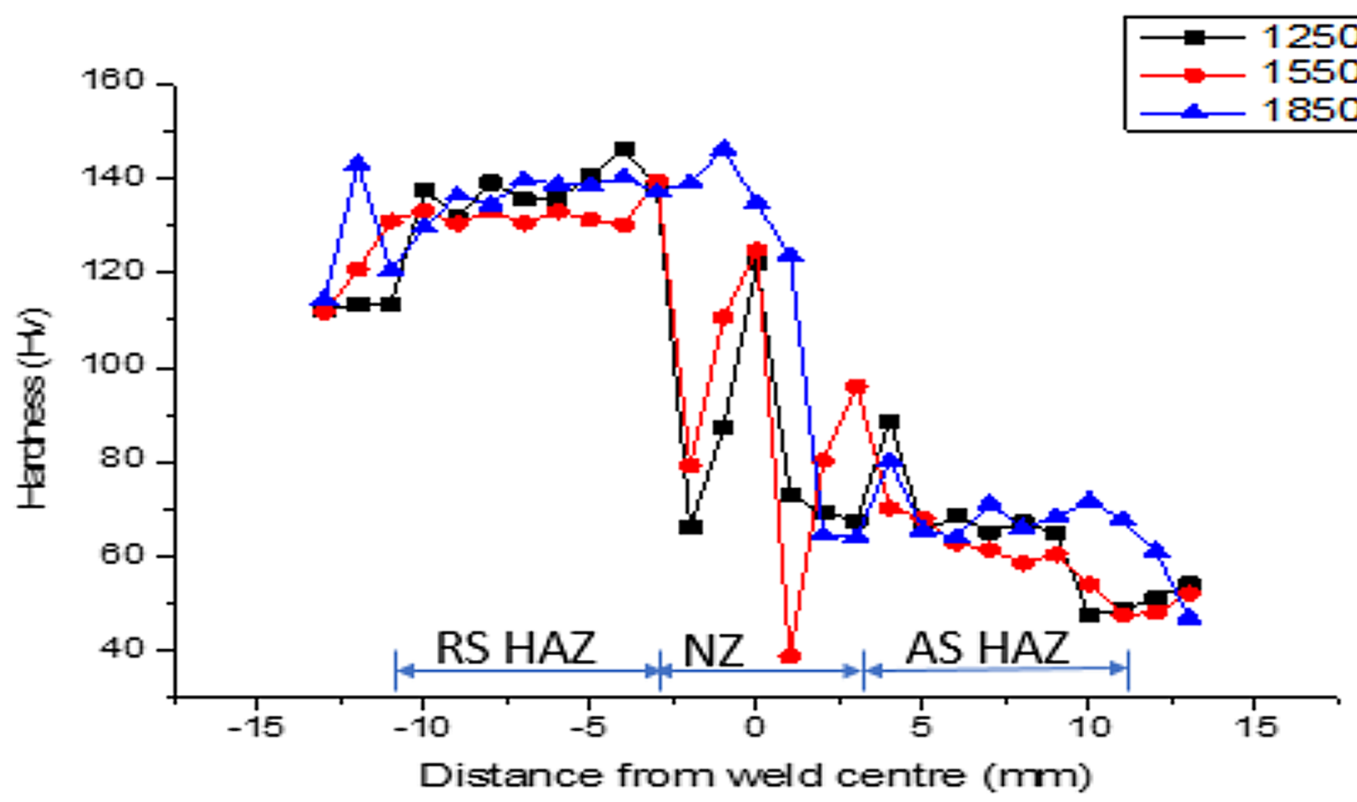

Fig. 9. Hardness profile at varying rotational speed.

values of hardness obtained at that particular welding speed at the HAZ of the RS. At lower welding speeds, the thermal impact is felt more and development of coarse precipitates may occur resulting to decrease in hardness. At the nugget zone (NZ), the average hardness values at different welding speed were generally lower than the hardness of the 7075-T651 parent alloy but are higher than that of 6101-T6 parent alloy. This is due to the mixing of both alloys at this region. The hardness at the NZ increased to a maximum of $122.62 \mathrm{HV}$ as the welding speed increases to $65 \mathrm{~mm} / \mathrm{min}$ and drastically dropped to $83.56 \mathrm{HV}$ with further increase in welding speed to $110 \mathrm{~mm} \mathrm{~min}^{-1}$. The variation in the average hardness values in the NZ at different welding speed is due to inhomogeneous mixing of material compositions and distribution at the zone which could result to the dissolution of strengthening precipitates and hence lowering the hardness values in the zone as noticed at welding speeds of $20 \mathrm{~mm}$ and $110 \mathrm{~mm} \mathrm{~min}^{-1}$. The same transformation observed in the NZ took place in the HAZ of the advancing side. The average hardness value in the region at $20 \mathrm{~mm} / \mathrm{min}$ was $60.97 \mathrm{HV}$ which moved up to $81.88 \mathrm{HV}$ at $65 \mathrm{~mm} / \mathrm{min}$ before dropping to $58.71 \mathrm{HV}$ at the welding speed of $110 \mathrm{~mm} \mathrm{~min}^{-1}$. There is little or no difference between the average hardness values obtained at the HAZ of the AS and that of the parent alloy 6101-T6 at the AS. This may be due to the high thermal conductivity 


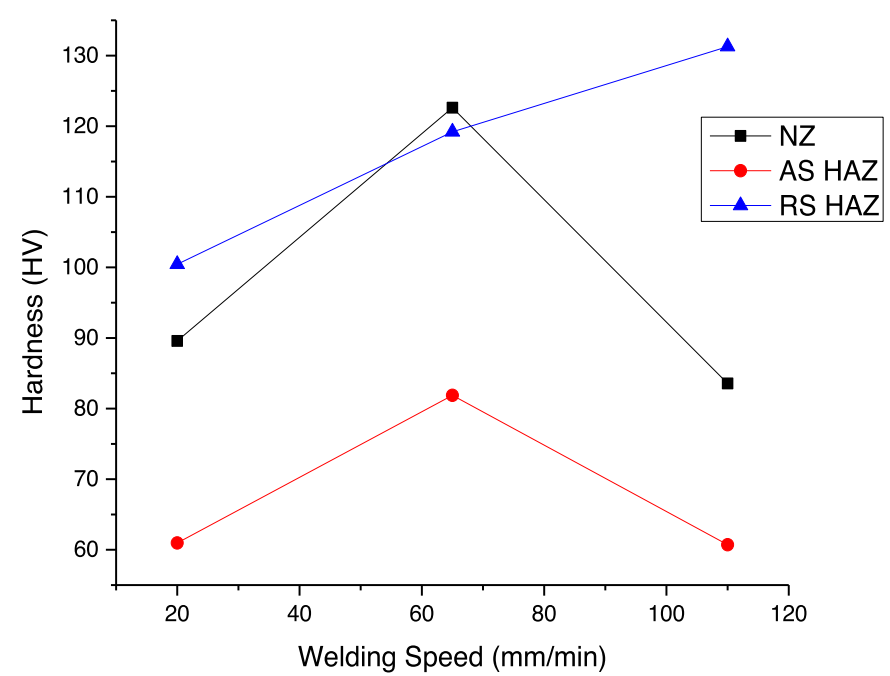

Fig. 10. Average hardness values at the NZ, AS HAZ and RS HAZ for the three different welding speed.

of the alloy which promotes heat dissipation from the welding process to the surrounding thereby reducing thermal stress set up in the region during welding. Lower values of average hardness recorded at a welding speed of $20 \mathrm{~mm} \mathrm{~min}^{-1}$ on the AS sides of the HAZ can be linked to precipitate coarsening due to slower traversing of the tool on the workpiece. Although higher traversing speed of $110 \mathrm{~mm} \mathrm{~min}^{-1}$ also led to lower average hardness values on AS of the HAZ. This suggests that there is a range of welding speed within which optimum hardness values can be obtained within the region.

\subsubsection{Hardness at different rotational speeds}

The hardness profile as shown in Figure 9 exhibit similar pattern of transformation across the RS of the HAZ, the NZ and the AS of the HAZ for the three different rotating speeds at a constant welding speed of $110 \mathrm{~mm} \mathrm{~min}^{-1}$. At the HAZ of the RS, the hardness values were highest but drop abruptly at the NZ. The least value of hardness at the NZ occurred at the rotation speed of $1550 \mathrm{rpm}$. This may be due to little void at the weld centre own to improper bonding of the transported grains at that point. Also, from Figure 11 at the HAZ of the RS, the average value of hardness is $131.27 \mathrm{HV}$ at $1250 \mathrm{rpm}$. This value decreases to $126.96 \mathrm{HV}$ as the rotational speed increase to $1550 \mathrm{rpm}$ and became maximum with $133.56 \mathrm{HV}$ at $1850 \mathrm{rpm}$. All the hardness values at the RS of the HAZ are lower than that of the parent alloy on the RS. Similar behaviour was observed for $\mathrm{HAZ}$ of the AS with an average hardness value of $60.71 \mathrm{HV}$ at $1250 \mathrm{rpm}$ which decreases to $58.41 \mathrm{HV}$ at $1550 \mathrm{rpm}$ and rose slightly up to $66.11 \mathrm{HV}$ at $1850 \mathrm{rpm}$. However, these values do not differ considerably from that of the parent alloy at the advancing side own to the high thermal conductivity of the alloy as explained earlier on in Section 3.2.1. A slightly different pattern was observed in NZ. The average hardness value increases as the tool rotational speed increases within the range of $83.56 \mathrm{HV}$ at $1250 \mathrm{rpm}$ to $122.46 \mathrm{HV}$ at $1850 \mathrm{rpm}$. The general drop in

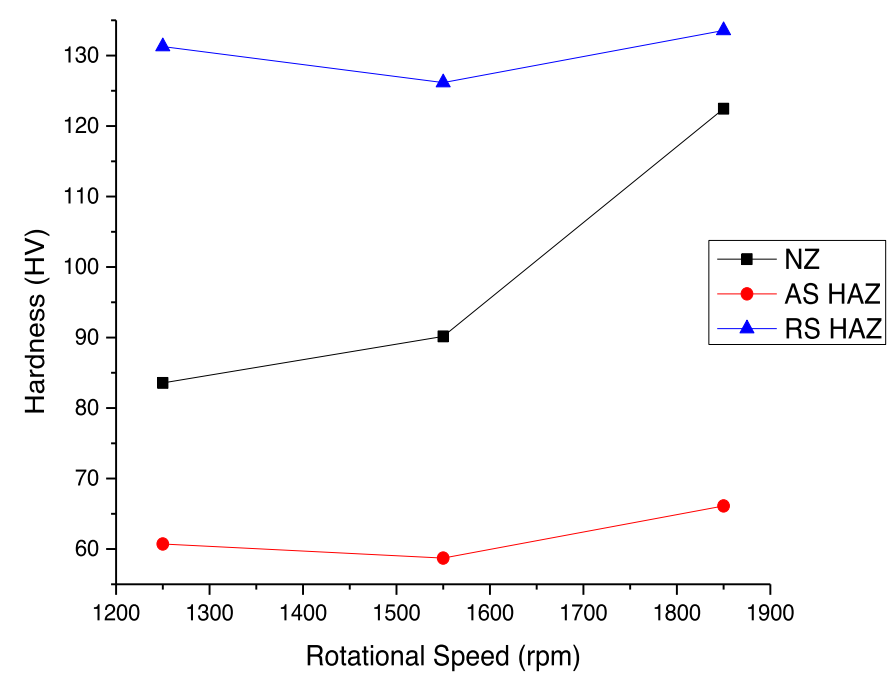

Fig. 11. Average hardness values at the NZ, AS HAZ and RS HAZ for the three different rotational speed.

hardness values on both sides of the HAZ at $1550 \mathrm{rpm}$ may not be unconnected with poor material mixing and coarsening of the precipitates at the zones during the welding.

\subsection{Wear behaviour}

MFTI7 software of the tribometer used generates the wear volume, depth and coefficient of friction while the wear rate and the wear resistance were calculated using equation (1) $[35,36]$. Table 4 shows the summary of the results obtained for the wear test for each processing parameter employed.

$$
\begin{aligned}
& \text { Wear rate }\left(\mathrm{mm}^{3} / \mathrm{Nm}\right) \\
& \qquad=\frac{\text { Wear volume }}{\text { Applied force } \times \text { Sliding distance }} \times 1000
\end{aligned}
$$

\subsubsection{Wear rate at different welding speeds}

The wear profiling as obtained from the tribometer software for the samples at different welding speeds are shown in Figure 16A a (i, ii), b (i, ii), and c (i, ii). The coefficient of friction (COF) responses of the weld at different welding speeds is shown in Figure 13. The COF at the three different welding speeds employed did not show a clear difference as the wear process progresses. The wear rate obtained at the different welding speeds for the samples $\mathrm{A}-\mathrm{C}$ as shown in Table 4 is much lower than those of the parent materials. The relationship between the welding speeds and wear rate as illustrated in Figure 14 indicate that there was a reduction in the wear rate as the welding speed increases to $65 \mathrm{~mm} \mathrm{~min}^{-1}$. However, a further increase in the speed to $110 \mathrm{~mm} \mathrm{~min}^{-1}$ resulted in appreciably high wear rate. This observation agreed with earlier findings by Palanivel et al. [23] and Dinaharan et al. [24]. The lowest wear rate at $65 \mathrm{~mm} \mathrm{~min}^{-1}$ can be ascribed to better material mixing and grain refinement at the 
Table 4. Summary of wear results obtained for different parameters.

\begin{tabular}{llllllll}
\hline Denotation & $\begin{array}{l}\text { Rotational } \\
\text { speed (rpm)/ } \\
\text { welding speed } \\
\left(\mathrm{mm} \mathrm{min}^{-1}\right)\end{array}$ & $\begin{array}{l}\text { Weight } \\
\text { of sample } \\
\text { before } \\
\text { testing }(\mathrm{g})\end{array}$ & $\begin{array}{l}\text { Weight } \\
\text { of sample } \\
\text { after } \\
\text { testing }(\mathrm{g})\end{array}$ & $\begin{array}{l}\text { Weight } \\
\text { loss }(\mathrm{g})\end{array}$ & $\begin{array}{l}\text { Wear } \\
\text { depth } \\
(\mathrm{mm})\end{array}$ & $\begin{array}{l}\text { Wear } \\
\text { volume } \times \mathrm{E}^{-2} \\
\left(\mathrm{~mm}^{3}\right)\end{array}$ & $\begin{array}{l}\text { Wear } \\
\text { rate } \times \mathrm{E}^{-4} \\
\left(\mathrm{~mm}^{3} \mathrm{Nm}^{-1}\right)\end{array}$ \\
\hline $\mathrm{A}$ & $1250 / 20$ & 4.3829 & 4.3825 & 0.004 & 0.04607 & 3.443031 & 1.9128 \\
$\mathrm{~B}$ & $1250 / 65$ & 4.3611 & 4.3609 & 0.002 & 0.0895 & 2.679846 & 1.4888 \\
$\mathrm{C}$ & $1250 / 110$ & 4.4723 & 4.4721 & 0.002 & 0.06762 & 6.813473 & 3.7853 \\
$\mathrm{D}$ & $1550 / 110$ & 3.9141 & 3.9138 & 0.003 & 0.05050 & 7.141568 & 3.9675 \\
$\mathrm{E}$ & $1850 / 110$ & 3.8586 & 3.8584 & 0.002 & 0.05675 & 3.098608 & 1.7215 \\
$6101-\mathrm{T} 6$ & - & 3.5621 & 3.562 & 0.001 & 0.06057 & 9.483394 & 5.2686 \\
$7075-\mathrm{T} 6$ & - & 4.7118 & 4.7119 & 0.001 & 0.10227 & 7.524306 & 4.1802 \\
\hline
\end{tabular}

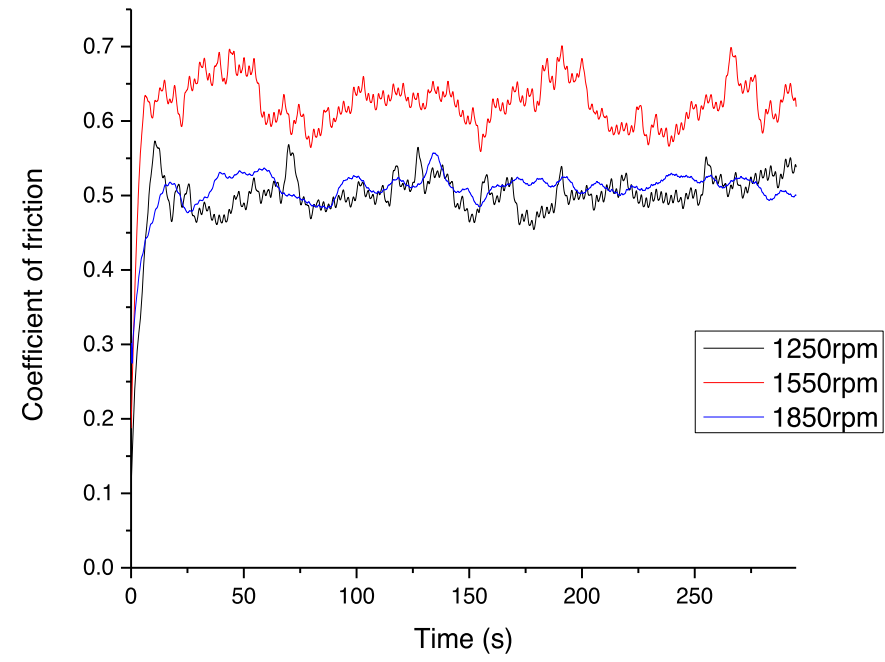

Fig. 12. Coefficient of friction responses at different tool rotational speed.

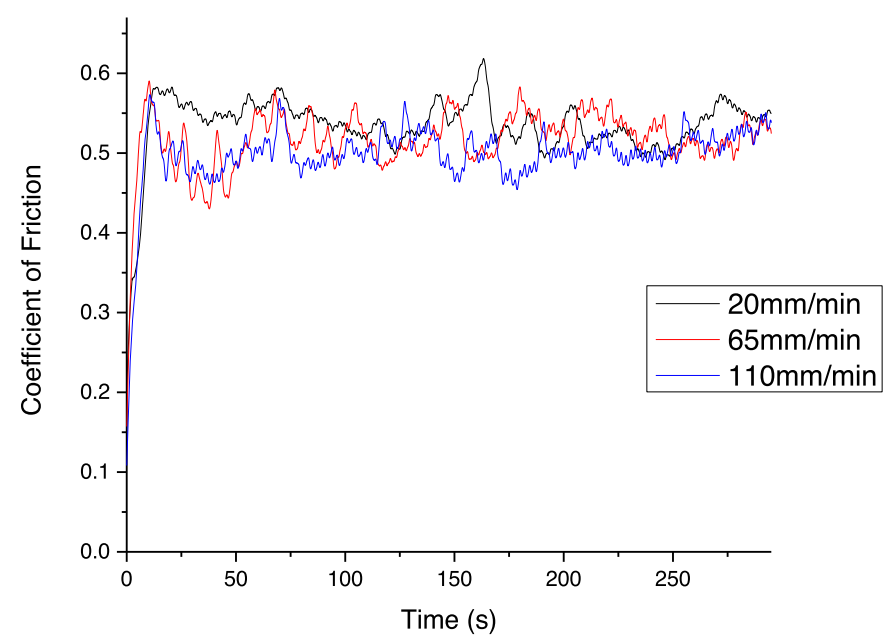

Fig. 13. Coefficient of friction responses at different welding speed.

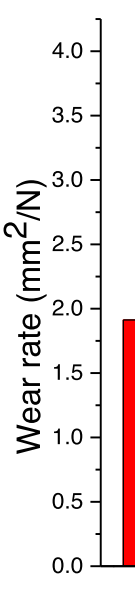

20

Welding speed $(\mathrm{mm} / \mathrm{min})$

Fig. 14. Wear rate at different welding speeds.

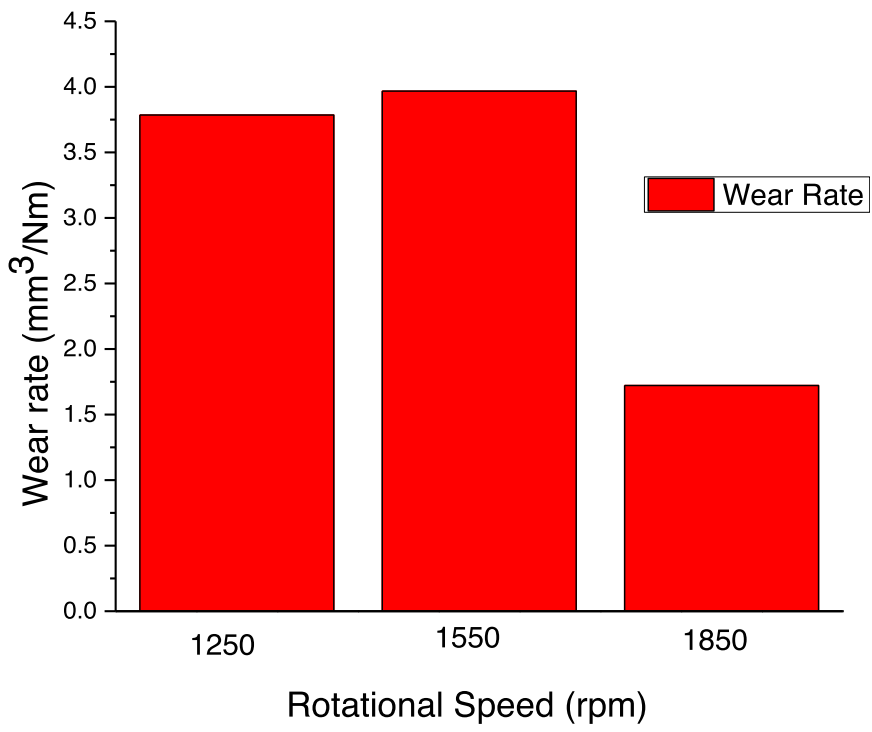

Fig. 15. Wear rate at different rotational speeds. 

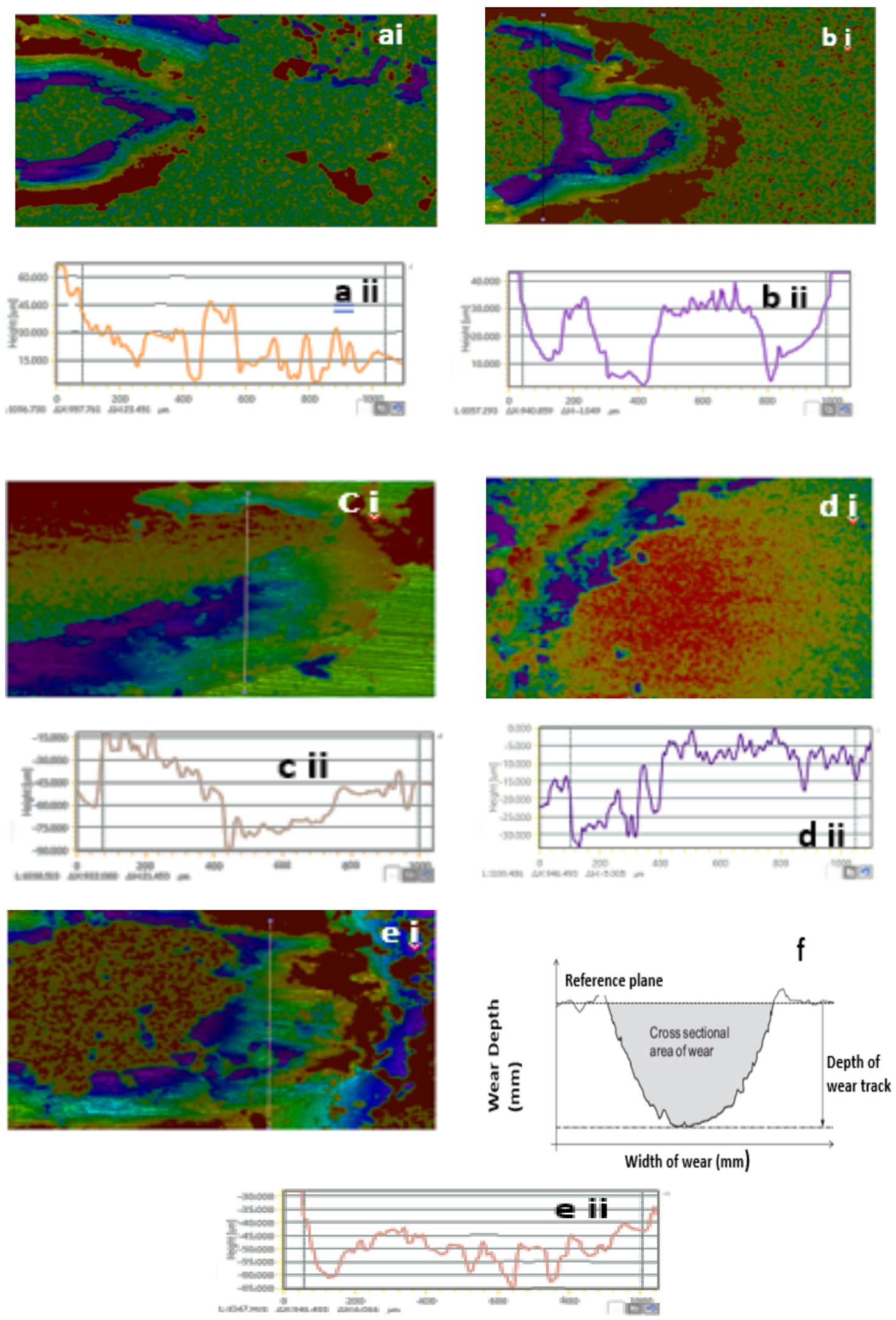

Fig. 16. Wear profiling (ai) and (aii) for sample A. (bi) and (bii) for sample B. (ci) and (cii) for sample C. (di) and (dii) for sample D. (ei) and (eii) for sample E. (f) Illustration of wear profile. 

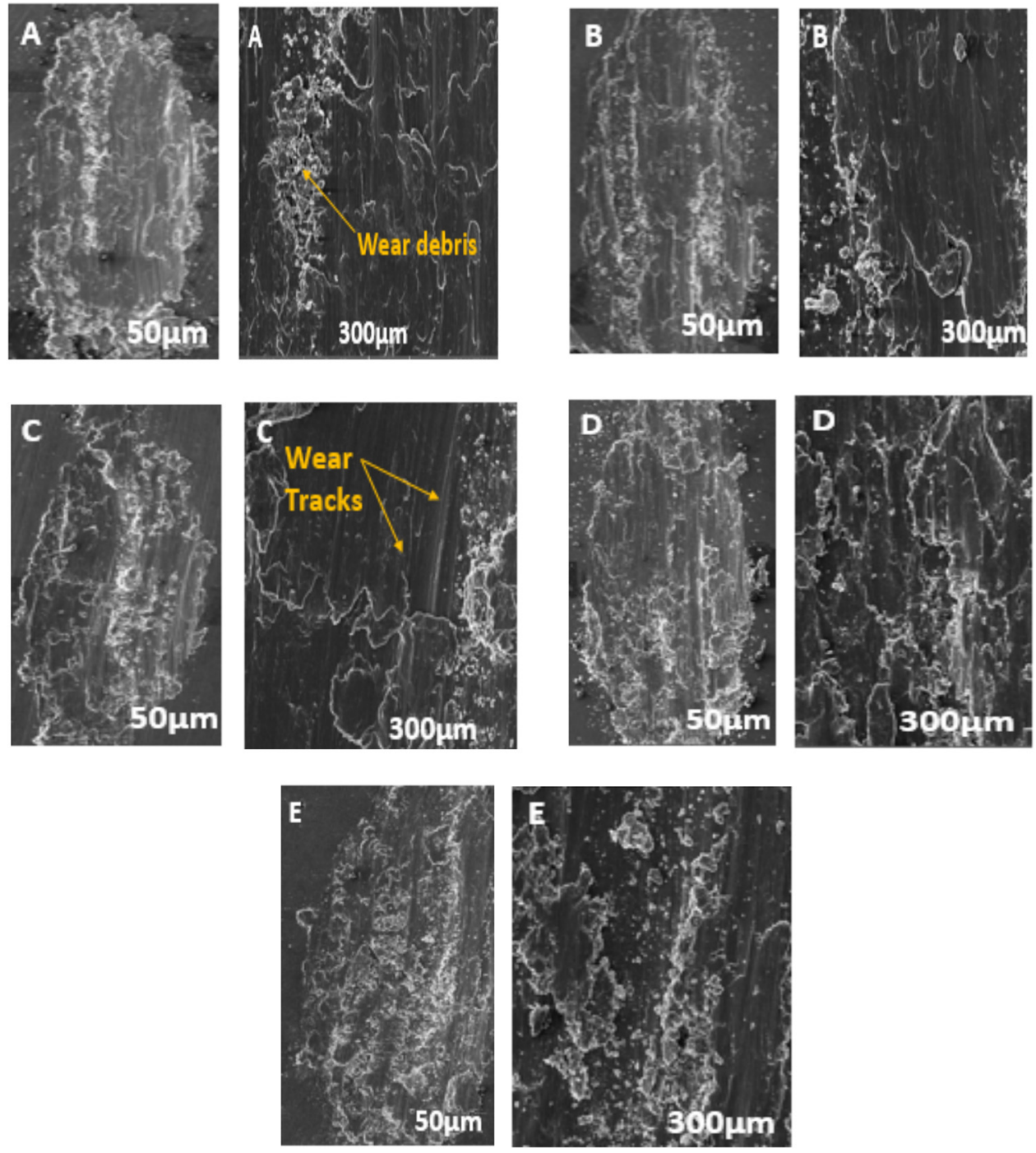

Fig. 17. SEM micrograph of wear tracks for sample A-E at different magnifications.

nugget zone. This finding also reflects in the high hardness values obtained at the nugget zone of the sample as illustrated in the hardness profile shown in Figure 9. This was in agreement with Gopi et al. [37] and Umasankar et al. [38] who affirmed that wear rate is inversely proportional to the hardness. The SEM micrographs of the samples at a different speed as indicated in Figure $17 \mathrm{~A}-\mathrm{C}$ similarly exhibit narrow and shallow grooves attributed to a lower coefficient of friction due to abrasion from entrapped debris and asperities on the hard counterbody.

\subsubsection{Wear rate at different rotational speeds}

The wear profiling as obtained from the tribometer software for the samples at different rotational speeds are shown in Figure 16 ci, c ii, di, d ii, e i and e ii. Calculated wear rates for the samples at different rotational speeds are shown in $\mathrm{C}, \mathrm{D}$ and $\mathrm{E}$ in Table 4. The coefficient of friction responses of the welds at different rotational speed as shown in Figure 12 indicate that the coefficient of friction was highest at the rotational speed of 1550 and minimum at $1250 \mathrm{rpm}$. The wear rate as observed in Figure 15 was highest in D at $1550 \mathrm{rpm}$. All these imply that more wear took place at the rotational speed of $1550 \mathrm{rpm}$ than the other two rotational speeds of 1250 and $1850 \mathrm{rpm}$. The high $\mathrm{COF}$ and wear rate observed at that speed is an indication of low resistance to wear. This is also evident in the hardness profile shown in Figure 9. The hardness values dropped at the nugget zone. The same zone where the wear test was carried out. This is another confirmation that hardness is inversely proportional to wear rate as reported by some authors $[24,25]$. The wear rate at the three rotational speeds studied was generally lower than those of the two parent metals. This can be attributed to grain refinement and proper material mixing and cohesion at the nugget zones own to thermal cycle impact from the welding process. The SEM micrographs at the different rotational speeds studied are shown in Figure $17 \mathrm{C}-\mathrm{E}$. The micrographs generally show mild adhesion mechanism with evidence of grooves but very narrow and shallow. 

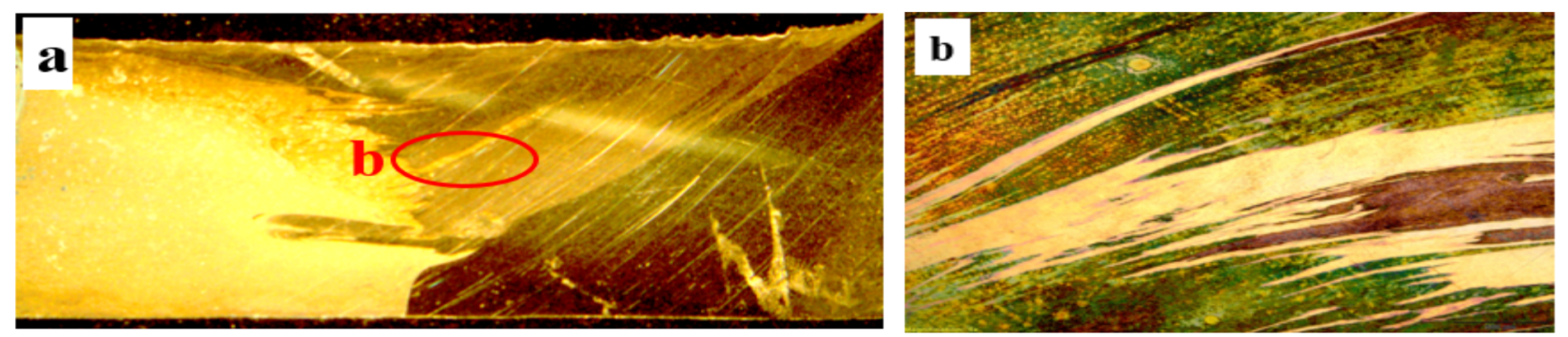

Fig. 18. Material flow at $1250 \mathrm{rpm}$ and $20 \mathrm{~mm} / \mathrm{min}$ (a) Macrograph (b) microstructures at $20 \mathrm{X}$.
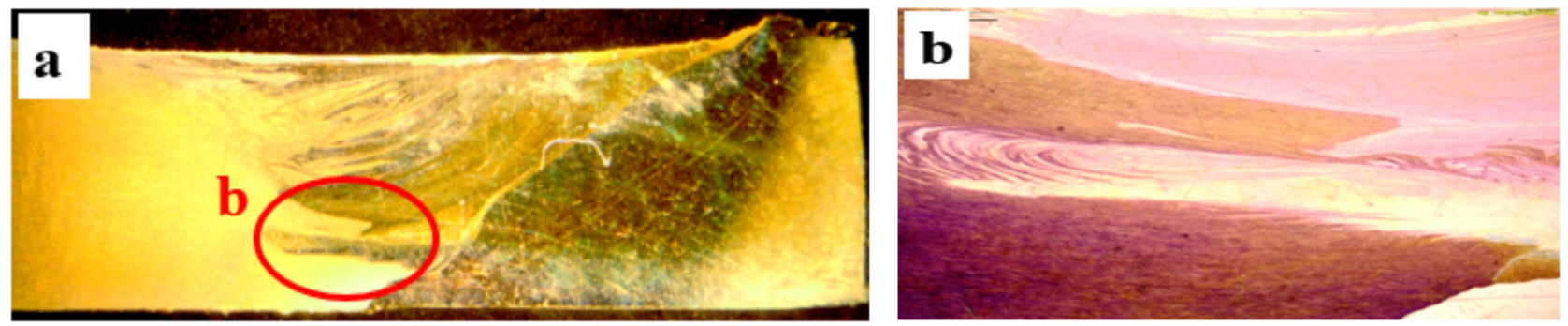

Fig. 19. Material flow at $1250 \mathrm{rpm}$ and $65 \mathrm{~mm} / \mathrm{min}$ (a) Macrograph (b) microstructures at 20X.
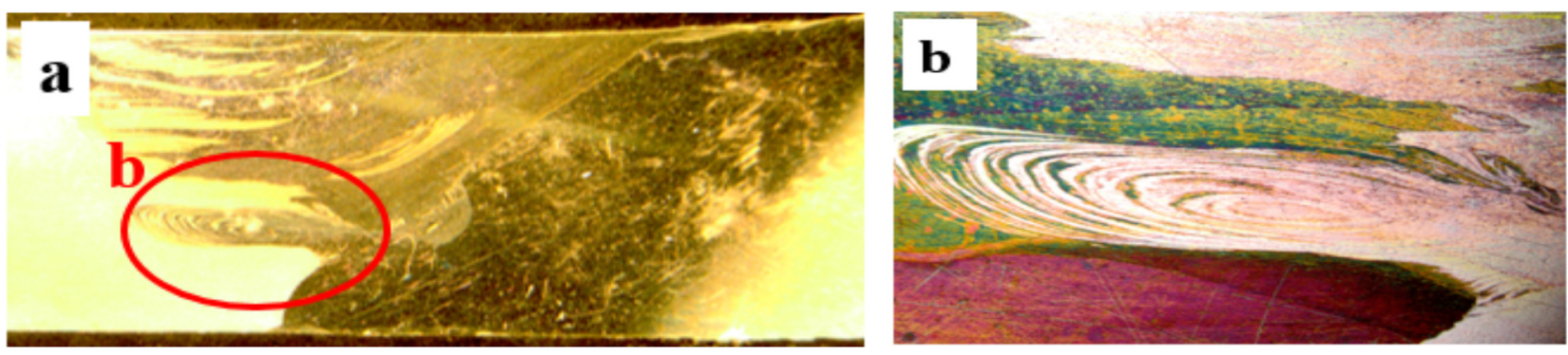

Fig. 20. Material flow at $1250 \mathrm{rpm}$ and $110 \mathrm{~mm} / \mathrm{min}$ (a) Macrograph (b) microstructures at $20 \mathrm{X}$.
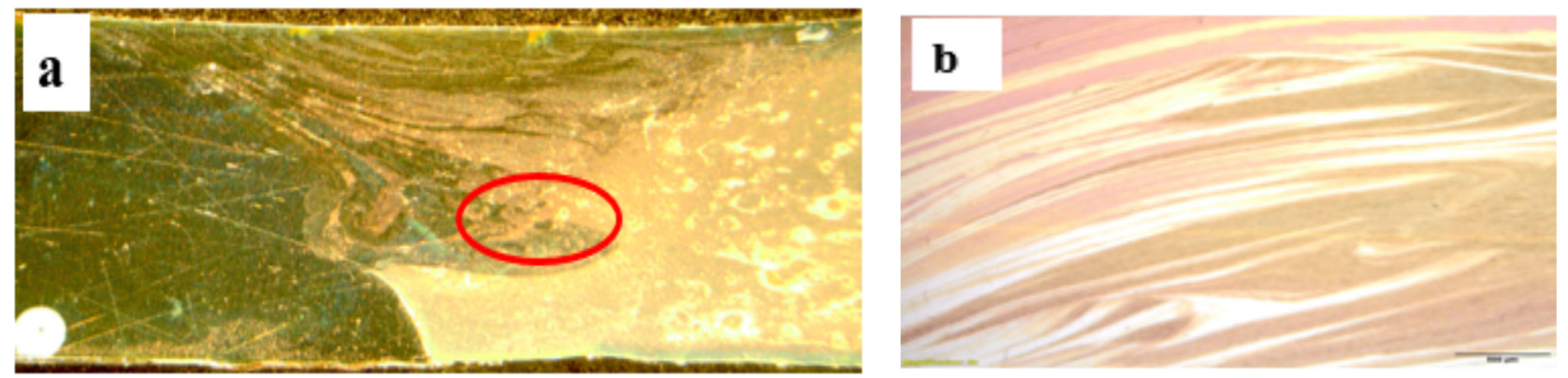

Fig. 21. Material flow at $1550 \mathrm{rpm}$ and $110 \mathrm{~mm} / \mathrm{min}$ (a) Macrograph (b) microstructures at $20 \mathrm{X}$.

\subsubsection{Microstructures}

The macrostructures and microstructures of each parameters obtained through an optical microscope are presented in Figures 18-22. The circled portions in Figures 18a, 19a, 20a, 21a and 22a are named "b" and are all magnified to $20 \mathrm{X}$ to give Figures 18b, 19b, 20b, 21b and 22b, respectively.
The macrographs for all the samples demonstrated nonuniformity in the material transportation from the upper weld region to the lower region as shown in Figures 18a, 19a, 20a, 21a and 22a. This may be attributed to variations in the contact area of the tool pin with the materials due to the tapered tool pin geometry used for the welding [39]. The weck's reagent used revealed 7075-T651 as a lighter colour 

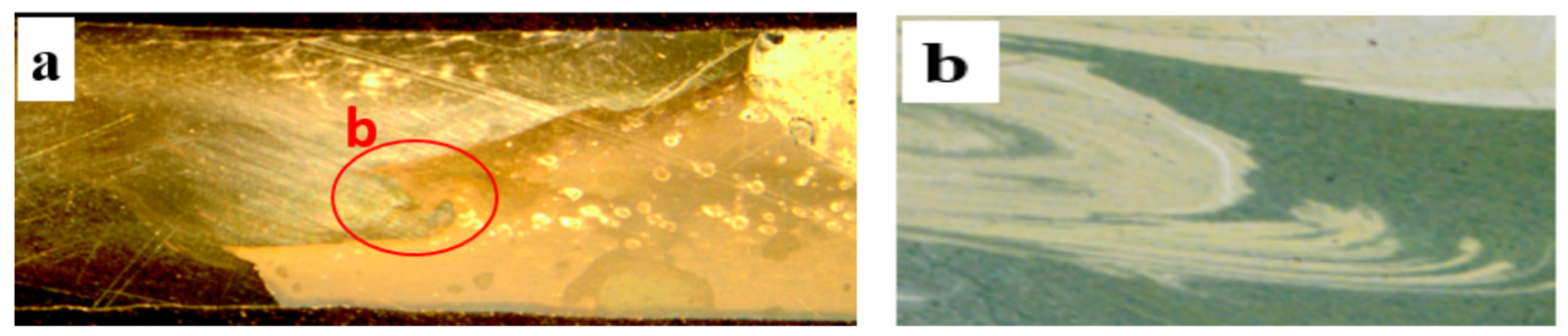

Fig. 22. Material flow at $1850 \mathrm{rpm}$ and $110 \mathrm{~mm} / \mathrm{min}$ (a) Macrograph (b) microstructures at $20 \mathrm{X}$.

while 6101-T6 is shown as a darker colour. The microstructures generally demonstrate appreciable material mixing at the nugget zone which promotes good bonding and disallowed the materials from fracturing at the welding joint during the tensile testing as explained earlier in Section 3.1.3. However, more layers of materials from the 6101-T6 on the advancing side of the weld seems to be swept more into the 7075-T651 on the retreating side at the weld at $1250 \mathrm{rpm}$ and $110 \mathrm{~mm} / \mathrm{min}$ (Fig. 20a). The mixing pattern of the alloys at the nugget zone at this parameter as observed in Figure 20b demonstrates alternate layers of the materials in a circular form which is often described as the "onion ring structures". These appreciable mixing and material flow pattern at the nugget zone of the weld could be correlated to the highest tensile value obtained at that parameter as given in Section 3.1.1 compared to the other parameters. On the contrary, at 1850rpm and $110 \mathrm{~mm} /$ min, considerable materials transportation and mixing was not properly achieved. Only the circled portion of the 6101T6 materials as shown in Figure 22a could be observed to extend into the 7075-T651 material compared to the other welds. This may be attributed not only to the higher rotational speed used but also due to the high traversing speed employed together for the weld which may not permit systematic interfacial mixing as the tool traverse faster on the joint interface of the alloys $[39,40]$. This also accounts for the lowest tensile value obtained at that parameter compared to other parameters used. The microstructures taken at the circled portion of the nugget zone of the micrographs revealed onion ring flow structures for $1250 \mathrm{rpm} / 65 \mathrm{~mm} / \mathrm{min}$ and $1250 \mathrm{rpm} / 110 \mathrm{~mm} / \mathrm{min}$ and alternate lamellae flow pattern for $1250 \mathrm{rpm} / 20 \mathrm{~mm} / \mathrm{min}$ and $1550 \mathrm{rpm} / 110 \mathrm{~mm} / \mathrm{min}$.

\section{Conclusion}

- The ultimate tensile values for dissimilar welds of 6101T6 and 7075-T651 have been found to decrease as the rotational speed increases but increase with an increase in travel speeds. These show that higher travel speed and lower rotational speed promote sound mechanical properties of the friction stir welded 6101-T6 and 7075-T651 aluminium alloys.

- All the tensile samples failed at the HAZ of the 6101-T6 alloy. The none failure of the material at the nugget zone indicates that good material mixing and bonding occurred considerably within the range of rotational and travel speeds deployed for this study.

- The hardness at the HAZ of both alloys was lower than those of their respective parent alloys. However, the hardness at the NZ was higher than that of the 6101-T6 parent alloy but lower than that of 7075-T651 parent alloy at all the rotational and welding speeds considered. Wear rate reduces as the welding speed increases. However, beyond a certain speed, the wear rate begins to increase. The highest resistance to wear was obtained at $65 \mathrm{~mm} / \mathrm{min}$ welding speed.

- The wear rate increases as the tool rotational speed increase to a level but reduce with a further increase in the rotational speed. The highest resistance to wear was obtained at a rotational speed of $1850 \mathrm{rpm}$.

\section{General comments}

A systematic relationship between tool rotational speed, traverse speed, wear behaviour, material flow and mechanical properties of friction stir welded 61010-T6 and 7075-T651 aluminium alloys have been established in this study. The observed correlation agrees with some findings in the literature on other dissimilar friction stir welding of aluminium alloys, This has widened the scope and understanding of dissimilar friction stir welding of aluminium alloys for lightweight industrial applications. However in-situ temperature measurement could not be carried out during the experiment for better understanding of the effects of the welding parameters on the thermal cycle set up and the accompanied microstructural modifications and mechanical behaviour.

\section{References}

1. W.M. Thomas ED, J.C. Nicolas, M.G. Needham, P. Murch, C. D. Templesmith, US Patent Application. 1995; No. 546031

2. W.M. Thomas ED, J.C. Nicolas, M.G. Needham, P. Murch, C. D. Templesmith, Int. patent Application. 1991. No.PCT/ GB92/02203

3. R.S. Mishra, Z.Y. Ma, Friction stir welding and processing, Mater. Sci. Eng. 50 (2005) 1-78

4. G. Buffa, L. Donati, L. Fratini, L. Tomesani, Solid-state bonding in extrusion and FSW: Process mechanics and analogies, J. Mater. Process. Technol. 177 (2006) 344-7 
5. P.H. Shah, V.J. Badheka, Friction stir welding of aluminium alloys: An overview of experimental findings - Process, variables, development and applications, Proc. Inst. Mech. Eng. Part L J. Mater. Des. Appl. 233 (2017) 1191-1226

6. T.A. Esther, A. Andrews, A.A. Stephen, Effects of processing parameters on the corrosion properties of dissimilar Friction Stir Welds of aluminium and copper, Trans. Nonferrous Met. Soc. China 24 (2014) 1323-1330

7. M. Sivashanmugam, S. Ravikumar, T. Kumar, V. Seshagiri Rao, D. Muruganandam, A review on friction stir welding for aluminium alloys. In: Proceedings of the International Conference on Frontiers in Automobile and Mechanical Engineering - 2010, FAME-2010, IEEE, New Jersey, 2010

8. S. Bocchi, M. Cabrini, G. D'Urso, C. Giardini, S. Lorenzi, T. Pastore, The influence of process parameters on mechanical properties and corrosion behaviour of friction stir welded aluminium joints, J. Manuf. Process. 35 (2018) 1-15

9. P. Cavaliere, A. De Santis, F. Panella, A. Squillace, Effect of welding parameters on mechanical and microstructural properties of dissimilar AA6082-AA2024 joints produced by friction stir welding, Mater. Des. 30 (2009) 609-616

10. P. Olatunji Abolusoro, E.T. Akinlabi. In-Process Cooling in Friction Stir Welding of Aluminium Alloys-An Overview. In: Al. MA et, editor. Advances in Material Sciences and Engineering, Lecture Notes in Mechanical Engineering, Springer Nature Singapore Pvt. Ltd., Berlin, 2020, 435-444

11. M.K.B. Givi, P. Asadi, Advances in Friction-Stir Welding and Processing (Elsevier, Amsterdam, 2014), 1-756

12. H. Lombard, D.G. Hattingh, A. Steuwer, M.N. James, Optimising FSW process parameters to minimise defects and maximise fatigue life in 5083-H321 aluminium alloy, Eng. Fract. Mech. 75 (2008) 341-54

13. M.S. Han, S.J. Lee, J.C. Park, S.C. Ko, Y.B. Woo, S.J. Kim, Optimum condition by mechanical characteristic evaluation in friction stir welding for 5083-O Al alloy, Trans. Nonferrous Met. Soc. China 19 (2009) 17-22

14. K.A. Prabha, P.K. Putha, B.S. Prasad, Effect of tool rotational speed on mechanical properties of aluminium alloy 5083 weldments in friction stir welding, Mater. Today Proc. 5 (2018) 18535-18543

15. H. Aydin, A. Bayram, U. Esme, Y. Kazancoglu, O. Guven, Application of Grey Relation Analysis (Gra) and Taguchi Method for the Parametric Optimization of Friction Stir Welding (Fsw) Process, Appl. Grey. Relat. Anal. 44 (2010) 205-11

16. M. Ghosh, K. Kumar, S.V. Kailas, A.K. Ray, Optimization of friction stir welding parameters for dissimilar aluminum alloys, Mater. Des. 31 (2010) 3033-3037

17. R. Hariharan, R.J. Golden Renjith Nimal, Friction stir welding oof dissimilar aluminium alloys $(6061 \& 7075)$ by using computerized numerical control machine, Middle-East J. Sci. Res. 20 (2014) 601-605

18. N.M. Daniolos, D.I. Pantelis, Microstructural and mechanical properties of dissimilar friction stir welds between AA6082-T6 and AA7075-T651, Int. J. Adv. Manuf. Technol. 88 (2017) 2497-505

19. E.G. Cole, A. Fehrenbacher, N.A. Duffie, M.R. Zinn, F.E. Pfefferkorn, N.J. Ferrier, Weld temperature effects during friction stir welding of dissimilar aluminium alloys 6061-t6 and 7075-t6, Int. J. Adv. Manuf. Technol. 71 (2014) 643-652
20. J.F. Guo, H.C. Chen, C.N. Sun, G. Bi, Z. Sun, J. Wei, Friction stir welding of dissimilar materials between AA6061 and AA7075 Al alloys effects of process parameters. Mater Des. 56 (2014) 185-192

21. M. Koilraj, V. Sundareswaran, S. Vijayan, S.R. Koteswara Rao, Friction stir welding of dissimilar aluminium alloys AA2219 to AA5083 - Optimization of process parameters using Taguchi technique, Mater. Des. 42 (2012) 1-7

22. S. Rajakumar, V. Balasubramanian, Establishing relationships between mechanical properties of aluminium alloys and optimised friction stir welding process parameters, Mater. Des. 40 (2012) 17-35

23. K. Elangovan, V. Balasubramanian, M. Valliappan, Influences of tool pin profile and axial force on the formation of friction stir processing zone in AA6061 aluminium alloy, Int. J. Adv. Manuf. Technol. 38 (2008) 285-295

24. D.A. Dragatogiannis, E.P. Koumoulos, I.A. Kartsonakis, D.I. Pantelis, P.N. Karakizis, C.A. Charitidis, Dissimilar Friction Stir Welding Between 5083 and 6082 Al Alloys Reinforced With TiC Nanoparticles, Mater. Manuf. Process. 31 (2016) 2101-2114

25. D.A. Dragatogiannis, D. Kollaros, P. Karakizis, D. Pantelis, J. Lin, C. Charitidis, Friction Stir Welding between 6082 and 7075 Aluminum Alloys Thermal Treated for Automotive Applications, Mater. Perform. Charact. 8 (2019)

26. L. Won-Bae, L. Chang-Yong, K. Myoung-Kyun, Y. Jung-I1, K. Young-Jig, Y. Yun-Mo JS-B, Microstructures and wear property of friction stir welded $\mathrm{AZ} 91 \mathrm{Mg} / \mathrm{SiC}$ particle reinforced composite, Compos. Sci. Technol. 66 (2006) 1513-1520

27. R. Palanivel, P.K. Mathews, N. Murugan, I. Dinaharan, Prediction and optimization of wear resistance of friction stir welded dissimilar aluminium alloy, Proc. Eng. 38 (2012) 578-584

28. M.N.I. Dinaharan, Influence of friction stir welding parameters on sliding wear behaviour of AA6061/0-10 wt.\% ZrB2 in-situ composite butt joints, J. Miner. Mater. Charact. Eng. 10 (2011) 1359-77

29. N. Syed Khaja, Md. A. Tousef, B.C. Purna, N. Mohan, Y.A. Vidhu Kampurath, Wear behaviour of welded and nonwelded samples of friction stir welding of similar and dissimilar joints of aluminium alloys, Int. J. Mech. Eng. Technol. 7 (2016) 289-299

30. S. Khaja Naimuddin, T. Md, K. Vidhu, M. Asim Mohamad, Y. Ali, Analysis of Wear Behaviourof the Friction Stir Welded Jointswith Varying Track Diametersfor NonWelded and Welded Samples, Indian J. Sci. Technol. 9 (2016) 41

31. G. Swaminathan, S. Sathiyamurthy, Experimental Study of Mechanical and Metallurgical Properties of Friction Stir Welded Dissimilar Aluminum Alloys, Int. J. Mech. Prod. Eng. Res. Dev. 8 (2018) 1049-1058

32. M.M. Abd Elnabi, A.B. Elshalakany, M.M. Abdel-Mottaleb, T.A. Osman, A.A. El Mokadem, Influence of friction stir welding parameters onmetallurgical and mechanical properties ofdissimilar AA5454-AA7075 aluminum alloys, J. Mater. Res. Technol. 8 (2019) 1684-1693

33. I. Kalemba-Rec, M. Kopys cianski, D. Miara, K. Krasnowski, Effect of process parameters on mechanical properties of friction stir welded dissimilar 7075-T651 and 5083-H111 aluminum alloys, Int. J. Adv. Manuf. Technol. 97 (2018) $2767-2779$ 
34. S. Rajakumar, C. Muralidharan, V. Balasubramanian, Influence of friction stir welding process and tool parameters on strength properties of AA7075-T6 aluminium alloy joints, Mater. Des. 32 (2011) 535-549

35. A.K. Shrivastava, K.K. Singh, A.R. Dixit, Tribological properties of $\mathrm{Al} 7075$ alloy and $\mathrm{Al} 7075$ metal matrix composite reinforced with $\mathrm{SiC}$, sliding under dry, oil lubricated, and inert gas environments, Proc. Inst. Mech. Eng. Part J. J. Eng. Tribol. 232 (2018) 693-698

36. F. Alshmri, H.V. Atkinson, S.V. Hainsworth, C. Haidon, S.D. A. Lawes, Dry sliding wear of aluminium-high silicon hypereutectic alloys, Wear 313 (2014) 106-116

37. V. Gopi, R. Sellamuthu, S. Arul, Measurement of hardness, wear rate and coefficient of friction of surface refined $\mathrm{Al}-\mathrm{Cu}$ alloy, Proc. Eng. 97 (2014) 1355-1360
38. U. Das, R. Das, V. Toppo, Wear behaviour study of Friction Stir Welded Dissimilar Metals: AA6101-T6 and AA6351-T6 Aluminium Alloys, IOP Conf. Ser. Mater. Sci. Eng. 377 (2018)

39. R. Palanivel, P. Koshy Mathews, N. Murugan, I. Dinaharan, Effect of tool rotational speed and pin profile on microstructure and tensile strength of dissimilar friction stir welded AA5083-H111 and AA6351-T6 aluminum alloys, Mater. Des. 40 (2012) 7-16

40. S. Ravikumar, V. Seshagiri Rao, R.V. Pranesh, Effect of Process Parameters on Mechanical Properties of Friction Stir Welded Dissimilar Materials between AA6061-T651 and AA7075-T651 Alloys, Int. J. Adv. Mech. Eng. 4 (2014) 101-114

Cite this article as: Olatunji P. Abolusoro, Esther T. Akinlabi, Effects of processing parameters on mechanical, material flow and wear behaviour of friction stir welded 6101-T6 and 7075-T651 aluminium alloys, Manufacturing Rev. 7, 1 (2020) 